\title{
Prevalence of swallowing dysfunction screened in Swedish cohort of COPD patients
}

\author{
This article was published in the following Dove Press journal: \\ International Journal of COPD \\ 17 January 2017 \\ Number of times this article has been viewed
}

\author{
Margareta Gonzalez Lindh ${ }^{1,2}$ \\ Monica Blom Johansson' \\ Margareta Jennische' \\ Hirsh Koyi ${ }^{2,3}$ \\ 'Department of Neuroscience, Speech \\ and Language Pathology, Uppsala \\ University, Uppsala, Sweden; ${ }^{2}$ Centre \\ for Research and Development \\ (CFUG), Uppsala University, County \\ Council of Gävleborg, Gävle, Sweden; \\ ${ }^{3}$ Department of Respiratory Medicine, \\ Gävle Hospital, Gävle, Sweden
}

Correspondence: Margareta Gonzalez Lindh

Department of Neuroscience, Speech and Language Pathology, Uppsala University, Box 593, 75I 24 Uppsala, Sweden

Tel +46 26 I55 195

Email margareta.gonzalez.lind@ regiongavleborg.se
Background: COPD is a common problem associated with morbidity and mortality. COPD may also affect the dynamics and coordination of functions such as swallowing. A misdirected swallow may, in turn, result in the bolus entering the airway. A growing body of evidence suggests that a subgroup of people with COPD is prone to oropharyngeal dysphagia. The aim of this study was to evaluate swallowing dysfunction in patients with stable COPD and to determine the relation between signs and symptoms of swallowing dysfunction and lung function (forced expiratory volume in 1 second percent predicted).

Methods: Fifty-one patients with COPD in a stable phase participated in a questionnaire survey, swallowing tests, and spirometry. A post-bronchodilator ratio of the forced expiratory volume in 1 second/best of forced vital capacity and vital capacity $<0.7$ was used to define COPD. Swallowing function was assessed by a questionnaire and two swallowing tests (water and cookie swallow tests).

Results: Sixty-five percent of the patients reported subjective signs and symptoms of swallowing dysfunction in the questionnaire and $49 \%$ showed measurable ones in the swallowing tests. For the combined subjective and objective findings, $78 \%$ had a coexisting swallowing dysfunction. No significant difference was found between male and female patients.

Conclusion: Swallowing function is affected in COPD patients with moderate to severe airflow limitation, and the signs and symptoms of this swallowing dysfunction were subjective, objective, or both.

Keywords: deglutition, deglutition disorders, swallowing, COPD, speech-language pathologist

\section{Introduction}

Chronic obstructive pulmonary disease (COPD) is presently the only endemic disease in Sweden where mortality is increasing, according to the statistics of the Swedish Heart-Lung Association in 2013. The World Health Organization predicts that it will become the third leading cause of mortality worldwide in $2020 .^{1}$ An estimated 400,000-700,000 people in Sweden suffer from the disease, which is characterized by a progressive persistent airflow limitation. ${ }^{2}$ An exacerbation means a temporary worsening in the COPD symptoms. Each person diagnosed with COPD has roughly 1.8 exacerbations annually, which are treated in the Swedish health care system. ${ }^{3}$ Since an exacerbation inevitably leads to a worsening of lung function ${ }^{4}$ and an increased risk of mortality, ${ }^{5}$ decreasing the number of exacerbations is an important medical goal. The etiology of a COPD exacerbation is unclear in one-third of the cases. ${ }^{4}$

Swallowing and breathing are two complex processes that require a closely coordinated interaction of shared anatomical structures and physiological function. ${ }^{6}$ A normal swallow usually occurs in the beginning or middle of an exhalation when 
the breathing is interrupted by a short apnea of approximately 1 second. ${ }^{7}$ Shaker et $\mathrm{al}^{8}$ showed that subjects with COPD have a disrupted coordination between breathing and swallowing; they more often start their swallow in the inspiratory phase than do normal age-matched subjects. Oropharyngeal dysphagia is associated with an increased risk of aspiration pneumonia. ${ }^{9}$

Recent research focuses on the correlation between COPD and dysphagia and on the relationship between dysphagia and increased exacerbations ${ }^{10,11}$ because of the complex coordination of breathing and swallowing. Gross et $\mathrm{al}^{10}$ found several abnormal aspects of respiratory timing during swallowing in patients with stable COPD. These patients swallowed at points in their respiratory cycle that could promote prandial aspiration exacerbations. In their hospital-based case-control study, Terada et $\mathrm{al}^{12}$ reported that an abnormal swallow reflex was associated with more frequent exacerbations of COPD. Two recent studies suggest that the duration of the events of the pharyngeal phase of swallowing is longer in COPD patients than in healthy controls when assessed through videofluoroscopic examination. ${ }^{13,14}$ This substantiates earlier research that dysphagia may be underdiagnosed in the COPD population. ${ }^{15-17}$ Furthermore, Langmore et al ${ }^{18}$ showed that COPD was the strongest independent comorbidity predictor (odds ratio $=2.49$ ) for aspiration pneumonia in nursing home patients.

Cvejic et $\mathrm{al}^{19}$ provide one of the most convincing evidences to date of aspiration during swallowing in patients with stable and moderate COPD. They followed 16 patients with COPD in a case-control study using videofluoroscopy while monitoring respiration. Hospitalization and mortality were assessed at 36 months. Patients with COPD were more likely to have either penetration of pharyngeal contents into the larynx or actual aspiration when swallowing large fluid volumes $(100 \mathrm{~mL})$. Both of these were associated with tachypnea, reduced hyoid elevation, post-swallow pharyngeal residue, and a trend toward an adverse outcome.

The aim of our study was threefold:

1. to examine the prevalence of swallowing dysfunction in a Swedish cohort of COPD patients with moderate to very severe airflow limitation, ie, Stages 2-4 according to the classification of the Global Initiative for Chronic Obstructive Lung Disease (GOLD); ${ }^{2}$

2. to analyze at what stage of the disease the patient started to experience problems with swallowing function; and

3 . to investigate gender differences in the number of dysphagia symptoms, ie, dysphagia burden.

\section{Materials and methods}

\section{Participants}

Patients were recruited consecutively between May 2011 and March 2012 while being at their scheduled appointment with either the COPD nurse or pulmonologist. All recruited patients had a spirometry-verified COPD diagnosis, a postbronchodilator ratio of the forced expiratory volume in $1 \mathrm{sec}-$ ond $\left(\mathrm{FEV}_{1}\right)$ /forced vital capacity $(\mathrm{FVC})<0.7$ of predicted, and were in a stable phase of the disease, defined as no exacerbations for at least 3 months before being included in the study. Patients with a previous history of head/neck cancer, stroke, lung cancer, dementia, and neuromuscular disease were excluded. The 51 recruits were 21 males (41.2\%) and 30 females $(58.8 \%)$. Thirteen patients $(26 \%)$ had moderate COPD (GOLD, Grade 2), 17 (33\%) had severe COPD (Grade 3), and 21 (41\%) were in a very severe stage of the disease (Grade 4). The study population characteristics are presented in Table 1. Only patients taking their full nutrition (liquid and solid) by mouth were enrolled in the study. The study protocol, questionnaires and informed consent were approved by the Regional Ethical Review Board, Uppsala University, Uppsala, Sweden (Dnr2014/405).

\section{Procedure}

After obtaining written informed consent, data were collected in a clinical environment by one speech-language pathologist (SLP). Spirometries were performed by the COPD nurses.

The following investigations were included:

- Spirometry test

- Two-part questionnaire

- Swallowing tests

\section{Pulmonary function}

Predicted normal values of the spirometry depend on gender, age, height, mass, and ethnicity and are expressed in percentage. With the GOLD standard, we classified the airflow limitation in COPD patients as moderate when post-bronchodilator $\mathrm{FEV}_{1}$ was between $50 \%$ and $80 \%$ of the predicted value,

Table I Patient characteristics

\begin{tabular}{llll}
\hline Variable & Mean & SD & Range \\
\hline Age, years & $7 \mathrm{I}$ & 7.7 & $52-84$ \\
$\mathrm{BMI}, \mathrm{kg} / \mathrm{m}^{2}$ & 24 & 5.9 & $15-40$ \\
$\mathrm{FEV}, \mathrm{L}$ & 1.02 & 0.6 & $0.37-3.49$ \\
$\mathrm{FEV} \%$ & $42.5 \mathrm{I}$ & 13.7 & $22.38-52.56$ \\
Swallowing capacity, $\mathrm{mL} / \mathrm{sec}$ & 15.36 & 11.9 & $3.16-52.56$ \\
\hline
\end{tabular}

Abbreviations: BMI, body mass index; $\mathrm{FEV}_{1}$, forced expiratory volume in I second. 
severe between $30 \%$ and $50 \%$, and very severe below $30 \%$ (or below $50 \%$ with defined negative prognostic factors). Our aim was to include patients with mild COPD ( $\mathrm{FEV}_{1} \geq 80 \%$ predicted), but this patient group is not generally found in specialized pulmonary clinics since their symptoms are discreet and easily interpreted, e.g. a common cold.

\section{Spirometry and disease severity in COPD}

Spirometry was performed with a dry volume spirometer (Welch Allyn, Skaneateles Falls, NY, USA; Spiro Perfect module) according to the Swedish COPD guidelines. A postbronchodilator ratio of $\mathrm{FEV}_{1}$ /best of $\mathrm{FVC}$ and vital capacity (VC) $<0.7$ was used to define COPD. Swedish reference values ${ }^{20}$ were applied for the $\mathrm{FEV}_{1}$. The severity grading for the airway limitation was based on the highest $\mathrm{FEV}_{1}$ and expressed as a percentage of the predicted value as defined by GOLD. ${ }^{2}$

\section{Questionnaire}

The questionnaire designed for the study consisted of questions routinely used by SLPs to identify dysphagia symptoms and risk factors during clinical evaluation (Table 2). At the time, there was no validated dysphagia questionnaire available in Sweden. Subjects were only asked to give a yes or no response since the aim was to look at prevalence and not the degree of possible swallowing dysfunction. Question 8 about serving size is a very subjective measurement. To reduce the subjectivity of the answers, participants were asked about the number of potatoes and meatballs they would normally serve themselves. After discussions with two of the hospital's dietitians, we defined the lower limit to one potato and six meatballs. Anything less than that was considered a small serving. Questions 1, 2, and 7 were selected for correlation with lung function. These three symptoms are some of the strongest clinical signs for identifying oropharyngeal dysphagia. ${ }^{21}$

Table 2 Result from the questionnaire

\begin{tabular}{llll}
\hline Questionnaire & $\mathbf{N}$ & $\%$ & $\mathbf{9 5 \%} \mathbf{C l}$ \\
\hline I. Coughing during meals & 18 & 35.7 & $22.4-49.9$ \\
2. Choking & 19 & 37.3 & $24.1-51.9$ \\
3. Dyspnea during meals & 11 & 21.6 & $11.2-35.3$ \\
4. Xerostomia & 36 & 70.6 & $56.2-82.5$ \\
5. Long meal duration & 25 & 49.0 & $34.7-63.4$ \\
6. Eats everything on the plate & 33 & 64.7 & $50.1-77.6$ \\
7. Bolus retention; mouth and/or pharynx & 18 & 35.3 & $22.4-49.9$ \\
8. Small servings & 23 & 45.1 & $40.3-68.9$ \\
9. Diminished appetite & 23 & 45.1 & $40.3-68.9$ \\
\hline
\end{tabular}

Note: Number of patients with subjective symptoms described in percent with a $95 \% \mathrm{Cl}$.

Abbreviation: $\mathrm{Cl}$, confidence interval.

\section{Swallowing tests}

Water swallow test

There is no validated dysphagia screening for COPD patients, so a timed test of swallowing capacity was used. This swallowing capacity test has a high intra- and interrater and test-retest reliability, with a sensitivity of $96 \%$ in neurogenic dysphagia. ${ }^{22}$ It does not discriminate between sensory and motor dysfunction, and it only measures swallowing capacity for liquids. The patient is asked to swallow $150 \mathrm{~mL}$ cold water as quickly as possible. Time is measured from the "go" signal to the last swallow, as recognized by return of the larynx to the rest position (seen exteriorly by the movement of the thyroid cartilage). Any coughing during or after the test and any changes in the quality of the voice after the test is noted. A swallowing capacity index of $10 \mathrm{~mL} / \mathrm{sec}$ is regarded to be the lower normal level. After performing the water swallow test, subjects were categorized into two groups: those with a swallowing capacity that is considered to be within normal limits ( $\leq 15$ seconds) and those who performed the test $>15$ seconds.

\section{Cookie swallow test}

Patients were asked to eat a dry cookie at their own pace and report any perception of retention in the mouth, pharynx, or esophagus. Any coughing or self-reported retention was scored as a "fail". All patients completed both swallowing tests.

\section{Statistical analysis}

Descriptive and comparative statistical calculations were made through SPSS statistics, version 21 (IBM, Armonk, NY, USA), and in Microsoft Excel 97-2003, Windows version 20 (Microsoft Corporation, Redmond, WA, USA). Microsoft Excel 97-2003 was also used for graphic presentation. Demographic data are reported as means, standard deviation, and range. The Mann-Whitney U test was used to test the difference in lung function between the group that performed the swallowing capacity test in $>15$ seconds and the group $\leq 15$ seconds (normal). This test was used because the data were unevenly distributed and the groups were small.

Spearman's rank correlation coefficient was used to examine the correlation between lung function $\left(\mathrm{FEV}_{1} \%\right)$ and:

- Patients' subjective experience of suboptimal swallowing function manifested by coughing, choking, or bolus retention.

- Objectively assessed dysphagia (swallowing capacity test and cookie test). 
- Both subjective and objective symptoms taken together.

The Mann-Whitney U test was also used to analyze whether the total number of dysphagia symptoms differed for men and women.

\section{Results}

The following variables are included in the analysis:

- Subjective symptoms: questionnaire

- Test of liquid swallowing capacity (volume/sec): normal index $=10 \mathrm{~mL} / \mathrm{sec}$

- Test of solid bolus (cookie): coughing, choking, and/ or bolus retention on solid bolus (oral, pharyngeal, and esophageal)

- Lung function (spirometry): $\mathrm{FEV}_{1} \%$ predicted, $\mathrm{FEV}_{1} / \mathrm{VC}$.

\section{Prevalence of self-reported swallowing dysfunction}

Thirty-three of the 51 participants $(65 \%)$ gave a positive answer to all or some of Questions 1,2, and 7 in the questionnaire (Table 2). Each of these questions had a positive response rate of approximately $36 \%$. Twelve percent of the patients experienced all three of the symptoms. We chose to use these three questions for correlation with lung function. A further analysis showed that it was not altogether the same patients who experienced problems with choking, coughing, and bolus retention.

\section{Swallowing tests - objective symptoms}

In this group of patients $(n=51), 49 \%(n=25)$ showed signs or symptoms of swallowing dysfunction in either the cookie swallow test or the water swallow test, or both. Data extracted from the $150 \mathrm{~mL}$ water swallow test showed a subnormal swallowing speed in $35.3 \%$ of the patients (Figure 1). A clear tendency but no significant difference $(P=0.068)$ was found in lung function for the groups who performed the swallowing capacity test within normal limits ( $\leq 15$ seconds) and in $>15$ seconds. Fifteen of the participants (29\%) experienced problems with the cookie, either coughing or reported bolus retention.

\section{Subjective and objective symptoms taken together}

Table 3 shows the distribution of number of dysphagia symptoms - three subjective and two objective symptoms - in relation to lung function. There was a symptom prevalence of $78 \%$ when subjective and objective symptoms were added

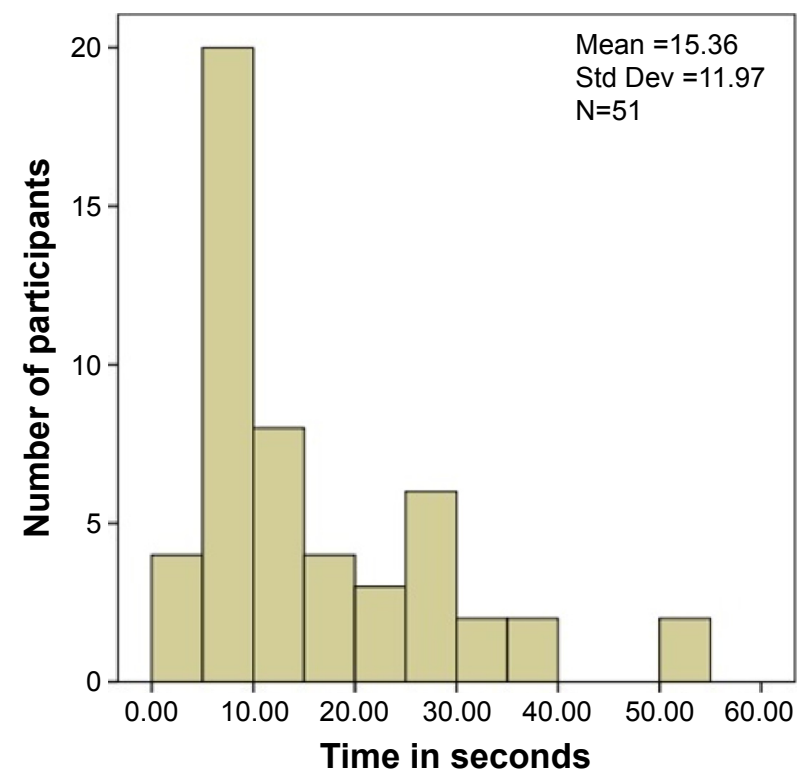

Figure I Histogram showing over swallowing capacity where the lower normal reference value for $150 \mathrm{~mL}$ of water is $10 \mathrm{~mL} / \mathrm{sec}$ ( $\leq 15$ seconds).

Note: The $y$-axis indicates the number of patients.

up but not graded. This includes patients with one or more symptoms.

\section{Statistically significant correlations}

There were significant correlations found for lung function $\left(\mathrm{FEV}_{1}\right)$ and the subjects' own experience of coughing, choking, and/or food getting stuck ( $\rho=-0.387, P=0.005$ ), the subjects' objective swallowing dysfunction $(\rho=-0.388$, $P=0.005)$, and combined dysphagia symptoms $(\rho=-0.477$, $P<0.001)$. Figure 2 shows the significant negative correlation between lung function and the five dysphagia symptoms. A decrease in the $y$-axis (lung function) correlates with an increase in the $x$-axis (number of symptoms).

\section{Gender difference in terms of number of dysphagia symptoms}

No significant difference was seen for male and female subjects regarding the number of dysphagia symptoms. The mean number of symptoms for men in this study was $2.05($ median $=2)$ and for women $1.5($ median $=1)$. The

Table 3 Results from the questionnaire and swallowing tests expressed in number of symptoms according to lung function

\begin{tabular}{llllllll}
\hline $\begin{array}{l}\text { Lung function } \\
\text { (GOLD) }\end{array}$ & $\begin{array}{l}\text { Number } \\
\text { (\%) }\end{array}$ & & I & $\mathbf{2}$ & $\mathbf{3}$ & $\mathbf{4}$ & $\mathbf{5}$ \\
\hline Stage 2 & $13(26)$ & 6 & 3 & 2 & $\mathrm{I}$ & $\mathrm{I}$ & 0 \\
Stage 3 & $17(33)$ & 5 & 7 & 2 & 2 & $\mathrm{I}$ & 0 \\
Stage 4 & $21(4 \mathrm{I})$ & 0 & 4 & 8 & 5 & 2 & 2 \\
Total & 51 & $11(22)$ & $14(28)$ & $12(24)$ & $8(16)$ & $4(8)$ & $2(4)$ \\
\hline
\end{tabular}

Abbreviation: GOLD, Global Initiative for Chronic Obstructive Lung Disease. 


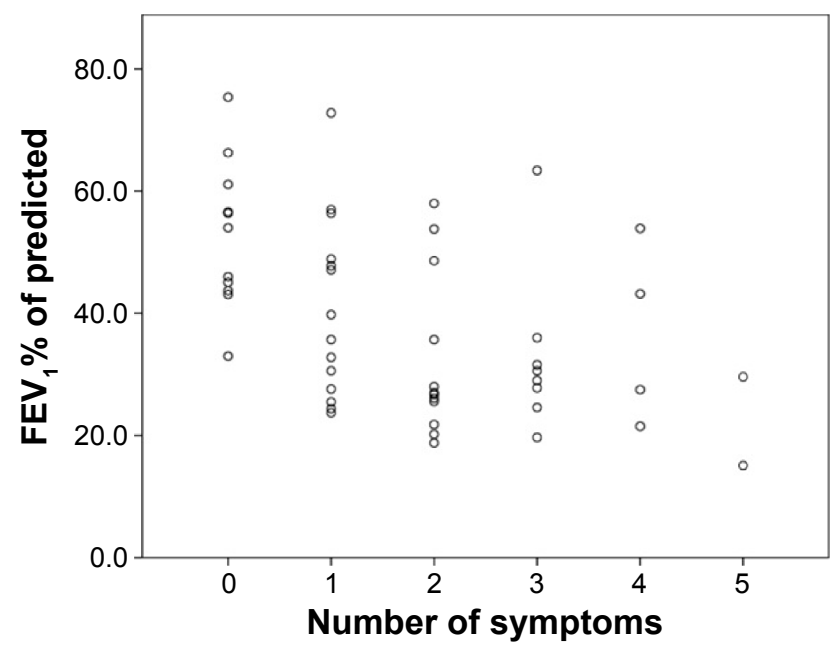

Figure 2 Scatterplot where the $y$-axis shows lung function expressed in $\mathrm{FEV} \%$, and the $x$-axis shows number of dysphagia symptom(s): subjective and objective symptoms.

Abbreviation: $\mathrm{FEV}_{1}$, forced expiratory volume in I second.

distribution between men and women within each group is illustrated in Table 4.

\section{Discussion}

This is, to our knowledge, the first study in Scandinavia to evaluate comprehensively the prevalence of swallowing dysfunction in patients with stable COPD. This study demonstrates that $78 \%$ of our patients with stable COPD were clinically at risk of dysphagia. This is significantly higher than the range $2.3 \%-16 \%$ in the general population recently reported by Kertscher et al. ${ }^{23}$

The prevalence of dysphagia in COPD patients varies in previous studies, ranging from $17 \%{ }^{17}$ to $85 \% .{ }^{15}$ One reason for this is the inclusion criteria where the patients' lung functions vary significantly in the studies. All patients in Coelho's study ${ }^{15}$ were in Stage 4 of the disease and tracheotomized. Another factor affecting the reported prevalence is whether the patient reports a swallowing problem in a questionnaire or if this has been evaluated instrumentally. The high prevalence noted in our study may be explained by the fact that the majority of patients were in Stages 3 or 4 of the disease, the

Table 4 Number of participants according to GOLD stage based on lung function $(\mathrm{FEV}, \%)$ and gender ratio

\begin{tabular}{llll}
\hline GOLD & FEV $\%$ of predicted & $\mathbf{N}(\%)$ & Male/female \\
\hline Stage 2 & $\geq 50 \%$ to $\leq-80 \%$ & I3 (26) & $7 / 6$ \\
Stage 3 & $\geq 30 \%$ to $<50 \%$ & $17(33)$ & $6 / I I$ \\
Stage 4 & $<30 \%$ & $21(4 I)$ & $8 / 13$ \\
Total & & $5 \mathrm{I}(100)$ & $2 \mathrm{I} / 30$ \\
\hline
\end{tabular}

Abbreviations: GOLD, Global Initiative for Chronic Obstructive Lung Disease; $\mathrm{FEV}_{1}$, forced expiratory volume in I second. mean age of the cohort was 71 years (standard deviation 7.7), the self-reported symptoms and the results from the swallowing tests were analyzed together, and the patients were asked to give a yes or no answer in the questionnaire. No other alternatives were allowed. Swallowing is a complex activity, and some patients may be absolutely asymptomatic regarding their deglutition. ${ }^{24} \mathrm{We}$ chose to analyze the signs or symptoms of swallowing dysfunction both subjectively as perceived by the patient and objectively through a screening test. We felt that one method alone would only explain one aspect of a multifaceted issue.

Our data showed a symptom range of 35\%-78\%. One reason for the discrepancy between subjective and objective symptoms could be simply that coughing is one of the most recognized signs of aspiration, and COPD patients are used to frequent coughing, as some of them pointed out. It might be difficult to distinguish a generic COPD cough from an aspiration cough, meaning that a chronic cough could potentially mask an aspiration. For these cases, we marked a "fail" in the cookie swallow test if a swallow was followed by a cough within 1 minute. For perceived bolus retention, data from Stein et $\mathrm{al}^{16}$ indicate that COPD patients have an increased risk of cricopharyngeal dysfunction, which often results in bolus retention in the sinus piriformis. In our study, 15 subjects (29\%) coughed or reported bolus retention. We decided not to further differentiate between these two symptoms since the groups would have been very small and required an instrumental examination not possible for this study. Our aim was to examine prevalence, not to grade a possible dysphagia. Therefore, the high prevalence reported covers the whole spectrum from mild to severe dysphagia symptoms.

The symptom with the highest prevalence was xerostomia (70.6\%), a condition that can cause dysphagia. We chose only to make a note of this but not to analyze it further. Xerostomia is a very common symptom in this patient group because almost all medication prescribed for COPD symptoms (eg, antibiotics, corticosteroids, diuretics, bronchodilators) can cause severe dry mouth: some patients choose to treat the condition and some do not.

We found a clear negative correlation between dysphagia burden expressed in number of dysphagia symptoms and lung function. The more signs and symptoms of a suboptimal swallowing, the worse the subject's lung function was (Table 3). In the group of participants with the best lung function (Stage 2), six of them had no signs or symptoms of dysphagia at all. In contrast, all participants in Stage 4 with a lung function of $\mathrm{FEV}_{1}<30 \%$ of predicted or 
$\mathrm{FEV}_{1}<50 \%$ of predicted and defined negative prognostic factors had one or several signs or symptoms of a swallowing problem. However, one might also argue that approximately half of the participants with the best lung function and in a stable phase of the disease still experienced some problems with swallowing.

An issue to be considered is the mean age of the participants (Table 1) since normal aging affects some parameters of swallowing and is considered to be an independent risk factor for a swallowing impairment. ${ }^{25}$ However, all our participants were ambulatory and lived at home and not in a nursing home.

In the past two decades, there has been a rapid increase in prevalence and mortality rates worldwide for COPD in women compared to men. ${ }^{26}$ Men and women also differ in the clinical symptoms. Men often report more sputum production, whereas health-related quality of life is lower for women than for men with COPD. ${ }^{27}$ However, in terms of swallowing capacity and dysphagia burden, we found no significant gender differences.

\section{Conclusion}

Of 51 participants with stable COPD assessed with simple swallowing tests and a questionnaire, a significant number, over $2 / 3$, demonstrated some swallowing difficulties. It is therefore recommended that COPD patients be asked if they experience any problems with swallowing while at their regular routine visit to the COPD nurse or pulmonary clinic.

We recognize that the water swallow and cookie swallow tests are screeners of dysphagia and not true diagnostic tests. The study would have been strengthened with the inclusion of an instrumental evaluation to better correlate biomechanical swallowing impairments and COPD, but this was unfortunately not an option. Although this might have inflated the prevalence of dysphagia due to false positives, our results show that some patients with COPD are prone to dysphagia while being in a stable phase of the disease. An unrecognized decreased swallowing capacity or prandial aspiration may precipitate or be an aggravating factor in exacerbations in these cases.

Further research should aim toward establishing data for improving health care outcomes, developing guidelines, and commissioning services for these patients.

\section{Acknowledgment}

Presented in part at the European Society for Swallowing Disorders Annual Meeting, Malmö, Sweden 2013.

\section{Disclosure}

The authors report no conflicts of interest in this work.

\section{References}

1. Mannino DM, Kiri VA. Changing the burden of COPD mortality. Int $J$ Chron Obstruct Pulmon Dis. 2006;1(3):219-233.

2. Vestbo J, Hurd SS, Agusti AG, et al. Global strategy for the diagnosis, management, and prevention of chronic obstructive pulmonary disease: GOLD executive summary. Am J Respir Crit Care Med. 2013;187(4):347-365.

3. Seemungal TAR, Hurst JR, Wedzicha JA. Exacerbation rate, health status and mortality in COPD - a review of potential interventions. Int J Chron Obstruct Pulmon Dis. 2009;4:203-223.

4. Decramer M, Janssens W, Miravitlles M. Chronic obstructive pulmonary disease. Lancet. 2012;379(9823):1341-1351.

5. Soler-Cataluna JJ, Martinez-Garcia MA, Roman Sanchez P, Salcedo E, Navarro M, Ochando R. Severe acute exacerbations and mortality in patients with chronic obstructive pulmonary disease. Thorax. 2005;60(11): 925-931.

6. Martin-Harris B, Brodsky MB, Michel Y, Ford CL, Walters B, Heffner J. Breathing and swallowing dynamics across the adult lifespan. Arch Otolaryngol Head Neck Surg. 2005;131(9):762-770.

7. Martin-Harris B. Coordination of respiration and swallowing. GI motility on line. 2006.

8. Shaker R, Li Q, Ren J, et al. Coordination of deglutition and phases of respiration: effect of aging, tachypnea, bolus volume, and chronic obstructive pulmonary disease. Am J Physiol. 1992;263(5 Pt 1):G750-G755.

9. Smithard DG, O'Neill PA, Parks C, Morris J. Complications and outcome after acute stroke. Does dysphagia matter? Stroke. 1996;27(7): $1200-1204$.

10. Gross RD, Atwood CW Jr, Ross SB, Olszewski JW, Eichhorn KA. The coordination of breathing and swallowing in chronic obstructive pulmonary disease. Am J Respir Criti Care Med. 2009;179(7):559-565.

11. Ghannouchi I, Speyer R, Doma K, Cordier R, Verin E. Swallowing function and chronic respiratory diseases: systematic review. Respir Med. 2016;117:54-64.

12. Terada K, Muro S, Ohara T, et al. Abnormal swallowing reflex and COPD exacerbations. Chest. 2010;137(2):326-332.

13. de Deus Chaves R, Chiarion Sassi F, Davison Mangilli L, et al. Swallowing transit times and valleculae residue in stable chronic obstructive pulmonary disease. BMC Pulm Med. 2014;14:62.

14. Cassiani RA, Santos CM, Baddini-Martinez J, Dantas RO. Oral and pharyngeal bolus transit in patients with chronic obstructive pulmonary disease. Int J Chron Obstruct Pulmon Dis. 2015;10:489-496.

15. Coelho CA. Preliminary findings on the nature of dysphagia in patients with chronic obstructive pulmonary disease. Dysphagia. 1987; 2(1):28-31.

16. Stein M, Williams AJ, Grossman F, Weinberg AS, Zuckerbraun L. Cricopharyngeal dysfunction in chronic obstructive pulmonary disease. Chest. 1990;97(2):347-352.

17. Good-Fratturelli MD, Curlee RF, Holle JL. Prevalence and nature of dysphagia in VA patients with COPD referred for videofluoroscopic swallow examination. J Commun Disord. 2000;33(2):93-110.

18. Langmore SE, Skarupski KA, Park PS, Fries BE. Predictors of aspiration pneumonia in nursing home residents. Dysphagia. 2002;17(4): 298-307.

19. Cvejic L, Harding R, Churchward T, et al. Laryngeal penetration and aspiration in individuals with stable COPD. Respirology. 2011; 16(2):269-275.

20. Berglund E, Birath G, Bjure J, et al. Spirometric studies in normal subjects. I. Forced expirograms in subjects between 7 and 70 years of age. Acta medica Scand. 1963;173:185-192.

21. Logemann JA. Evaluation and Treatment of Swallowing Disorders. 2nd ed. Austin, TX: Pro-Ed Inc; 1998. 
22. Nathadwarawala KM, Nicklin J, Wiles CM. A timed test of swallowing capacity for neurological patients. J Neurol Neurosurg Psychiatry. 1992 55(9):822-825.

23. Kertscher B, Speyer R, Fong E, Georgiou AM, Smith M. Prevalence of oropharyngeal dysphagia in the Netherlands: a telephone survey. Dysphagia. 2015;30(2):114-120.

24. Marchese-Ragona R, Restivo DA, Marioni G, Ottaviano G, Masiero S, Staffieri A. Evaluation of swallowing disorders in multiple sclerosis. Neurol Sci. 2006;27(4):s335-s337.
25. Robbins J, Hamilton JW, Lof GL, Kempster GB. Oropharyngeal swallowing in normal adults of different ages. Gastroenterology. 1992; 103(3):823-829.

26. Aryal S, Diaz-Guzman E, Mannino DM. COPD and gender differences: an update. Transl Res. 2013;162(4):208-218.

27. Raherison C, Tillie-Leblond I, Prudhomme A, et al. Clinical characteristics and quality of life in women with COPD: an observational study. BMC Womens Health. 2014;14(1):1-6.

\section{Publish your work in this journal}

The International Journal of COPD is an international, peer-reviewed journal of therapeutics and pharmacology focusing on concise rapid reporting of clinical studies and reviews in COPD. Special focus is given to the pathophysiological processes underlying the disease, intervention programs, patient focused education, and self management protocols.

\section{Dovepress}

This journal is indexed on PubMed Central, MedLine and CAS. The manuscript management system is completely online and includes a very quick and fair peer-review system, which is all easy to use. Visit http://www.dovepress.com/testimonials.php to read real quotes from published authors.

Submit your manuscript here: http://www.dovepress.com/international-journal-of-chronic-obstructive-pulmonary-disease-journal 